\title{
Determination of ultra-trace amounts of neonicotinoid insecticide imidacloprid by cyclic and square wave voltammetric methods using pretreated glassy carbon electrode
}

Ben Brahim M.*, Elahmadi M.F., Ammar H.B. and Samet Y.

Electrochemistry and Environmental Laboratory, Department of Materials Engineering, National Engineering School of Sfax, University of Sfax, B.P. 1173, 3038, Sfax, Tunisia

Received: 03/11/2017, Accepted: 20/06/2018, Available online: 26/09/2018

*to whom all correspondence should be addressed: e-mail: benbrahim.mabrouk@yahoo.com https://doi.org/10.30955/gnj.002509

\section{Abstract}

Pesticide production and application have progressively increased worldwide during recent decades. Among these compounds, imidacloprid (IMD) is a widely used insecticide in agriculture, and more particularly to control sucking insects in crops. The aim of this work is to develop rapid, simple and sufficiently sensitive cyclic voltammetry (CV) and square wave voltammetry (SWV) for the detection and quantification of this insecticide in water and agriculture samples. Pretreated glassy carbon electrode (PGC) was employed as working electrode. Aqueous solutions were prepared with Confidor 200-SL commercial formulation of IMD. Each voltammogram was characterized by a well-defined single irreversible cathodic peak at approximately $-1.38 \mathrm{~V} / \mathrm{SCE}$. The electrode reaction is mainly a diffusion controlled process. The optimization of experimental parameters such as IMD initial concentration, potential scan rate, $\mathrm{pH}$ and temperature was carried out by $\mathrm{CV}$, and then a comparative study was conducted by SWV. For the detection and quantification of IMD, the results obtained by SWV showed higher sensibility and accuracy than that by CV. The developed methods were successfully used to determine IMD in real samples, namely plum and peach juice.

Keywords: Neonicotinoid, cyclic voltammetry, square wave voltammetry, pretreated glassy carbon electrode, detection, quantification.

\section{Introduction}

The neonicotinoid 1[(6-chloro-3-pyridinyl) methyl]-Nnitro-2-imidazolidinimine is one of the most commonly used neonicotinoids for crop protection worldwide due to its low soil persistence and high insecticidal activity at very low application rate (Chao and Casida, 1997). It acts as antagonist by binding to postsynaptic nicotinic receptors in the insect's central nervous system resulting in the paralysis and death of insects (Matsuda et al., 2005). IMD is the active substance of many commercial insecticides such as Confidor, Gaucho, Prestige, Admire, and Provado (Tomlin, 2000). However, the intensive use of such insecticide in agriculture and the improper storage or disposal of obsolete insecticides is a source of environmental contamination. Many studies have demonstrated the existence of these insecticides and their residues in fruits and vegetables (Chin-Chen et al., 2009; Ting et al., 2004; Fernández et al., 2000; Obana et al., 2002; Mandic et al., 2005). For these reasons, several analytical techniques and treatment processes have been reported for the detection and the removal of IMD and its residues from water. High performance liquid chromatography (HPLC) [(Chin-Chen et al., 2009; Ting et al., 2004; Obana et al., 2002; Mandic et al., 2005; Baskaran et al., 1997), gas chromatography-mass spectrometry (GC-MS) (Alberto et al., 2011) and liquid chromatography-mass spectrometry (LC-MS) (Fernández et al., 2000; Blasco et al., 2002; Di Muccio et al., 2006; Fidente et al., 2005) are commonly used methods for the detection of IMD. Photochemical-fluorimetric method (Vilchez et al., 1998; Vilchez et al., 2001) and enzymelinked immunosorbent assay (Lee et al., 2001) were also utilized. These instrumental methods are accurate but expensive and time consuming, requiring lengthy sample extraction and cleanup procedures. Various electrochemical methods have been proposed for the determination of IMD, including square wave adsorptive stripping voltammetry (SWASV) (Guiberteau et al., 2001) cyclic voltammetry (CV) (Valeria et al., 2005; Wang and Zhang, 2012; Jin and Hu, 2008; Wu et al., 2013), differential pulse voltammetry (DPV) (Kumaravel and Chandrasekaran, 2011; Wu et al., 2013; Zsigmond et al., 2009; Majidi et al., 2011) and differential pulse polarography (DPP) (Alberto et al., 1999). Different electrode materials such as glassy carbon, carbon paste, carbon ceramic and mercury were used as cathodes for the determination of IMD. This determination can be based on the irreversible reduction of the electroactive nitro group to hydroxylamine and amine. The limit of detection (LOD) of this pesticide is dependent on the electrode materials and the 
electrochemical techniques. The lower LOD measured is about $0.01 \mu \mathrm{M}$ at mercury electrode using DPP method (Alberto et al., 1999). However, for environmental concerns the use of mercury electrode is not advisable. At a glassy carbon electrode, LOD is about $30 \mu \mathrm{M}$ using the cyclic voltammetric technique (Valeria et al., 2005). This value is too high for carrying out trace analysis. However, because of its high electrical conductivity, impermeability to gases, high chemical resistance, reasonable mechanical and dimensional stability and widest potential range of all carbonaceous electrodes (McCreery, 1991). We have chosen this electrode to minimize the LOD of IMD by the optimization of several experimental parameters.

Cyclic and Square-wave voltammetry are among the most effective techniques for development of analytical procedures for several routine applications. These techniques are used for both quantitative and qualitative chemical analysis. They have several distinct advantages including a high sensitivity and rapidity of data acquisition. Furthermore, the analysis of the characteristic parameters of these techniques provides information on the mechanism, kinetics and thermodynamics of chemical reactions.

This paper describes fully validated, simple, rapid, selective and sensitive procedures for the determination of IMD employing SWV and CV at PGC electrode.

\section{Material and methods}

\subsection{Reagents}

All solutions containing different amounts of IMD taken from an emulsifiable concentrate (Confidor 200 SL Bayer Crop Science) containing $200 \mathrm{~g} \mathrm{~L}^{-1}$ IMD were prepared using water purified in Milli-Q Millipore system. These solutions were kept in the dark at $4^{\circ} \mathrm{C}$. The supporting electrolyte is sodium sulfate $\left(\mathrm{Na}_{2} \mathrm{SO}_{4}\right) 2 \mathrm{~g}$ $\mathrm{L}^{-1}$ provided by Biochem. Sulfuric acid and sodium hydroxide were supplied by Merck and added to the required $\mathrm{pH}$ values covering the $\mathrm{pH}$ range of 3-11. Prior to measurements, the reduction of the dissolved oxygen at the electrode was eliminated by purging solutions with nitrogen for $5 \mathrm{~min}$.

\subsection{Apparatus}

Cyclic and Square-wave voltammograms were performed using a potentiostat-galvanostat (VoltaLab PST050). A conventional three-electrode, a pretreated glassy carbon disk (PGC: $3 \mathrm{~mm}$ diameter, Tacussel) was used as working electrode. A platinum foil and saturated calomel electrodes were employed as counter and reference electrodes, respectively. The $\mathrm{pH}$ of the 5 solution was measured with a Hanna digital pH meter 301 with combination glass electrode.

\subsection{Pretreatment of the glassy carbon electrode}

Prior to each measurement, the PGC disk was mechanically polished with fine alumina powder $(0.05$ $\mu \mathrm{m})$ and washed with ultrapure water to remove any residual polish before transferring to the cell. In order to obtain an active surface and reproducible electrochemical response, the PGC electrode was subjected to potential cycling conditions in $2 \mathrm{~g} \mathrm{~L}^{-1}$ sodium sulfate between -2.0 and $+2.0 \mathrm{~V}$ at a higher scan rate of $5.0 \mathrm{~V} \mathrm{~s}^{-1}$ for $120 \mathrm{~s}$.

\subsection{Procedure for the determination of $I M D$ in fruits} samples

Plum and peach samples at the stage of maturation were obtained from the local market of Sfax City, Tunisia. These fruits were put into plastic bags and transported to the laboratory where they were immediately subjected to analysis. $200 \mathrm{~g}$ of samples were washed in ultrapure water, chopped into small pieces and pressed mechanically by braun MP-80 multipress juice extractor. The suspension was filtered through a $0.45 \mathrm{~mm}$ milli-pore filter (Watman filter paper), centrifuged for 20 min until a clear sample, then, the obtained juice was fortified by the IMD. The amount of IMD in the plum and peach juice was evaluated by the standard addition method. The IMD content in the fruits juice was determined from the calibration curve of IMD concentration vs. peak current. The $\mathrm{pH}$ of the juice extracted was modified to 7.0 with appropriate volumes of $\mathrm{NaOH}$ solution. Finally, $20 \mathrm{~mL}$ of the filtrate juice was added to the supporting electrolyte solution $\left(0.05 \mathrm{~mol} \mathrm{~L}^{-1}\right)$ in the voltammetric cell for measurement. All tests cited in this work were performed at $25^{\circ} \mathrm{C}$.

\section{Results and discussion}

\subsection{Cyclic voltammetry investigation}

Figure 1 shows the cyclic voltammogram of IMD recorded at a concentration of $0.5 \mathrm{~g} \mathrm{~L}^{-1}$ in $2 \mathrm{~g} \mathrm{~L}^{-1} \mathrm{Na}_{2} \mathrm{SO}_{4}$ solution. $\mathrm{A}$ single cathodic peak appears at about $-1.38 \mathrm{~V}$ (vs. SCE).

In the reverse scan, there is no oxidation peak in the selected potential range in accordance with an irreversible electrochemical process.

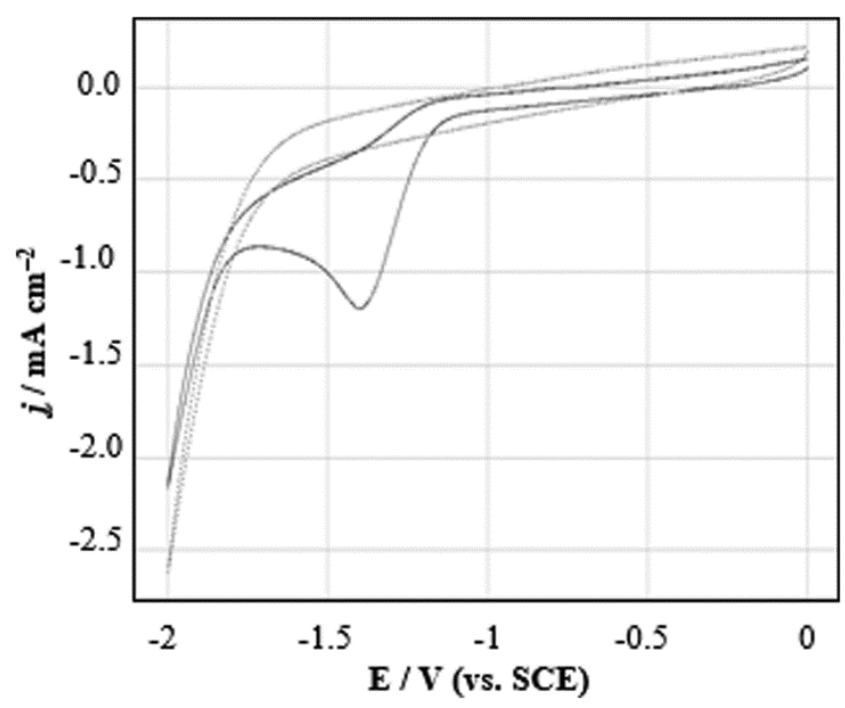

Figure 1. Voltammograms of the first cycle of the PGC electrode immersed in $2.0 \mathrm{~g} \mathrm{~L}^{-1} \mathrm{Na}_{2} \mathrm{SO}_{4}$ solution without (dotted curve) and with (solid curve) $0.5 \mathrm{~g} \mathrm{~L}^{-1} \mathrm{IMD}$. $\mathrm{pH}=7, v=100 \mathrm{mV} \mathrm{s}^{-1}$ and $T=$ 
Moreover, successive cycles (Figure 2) keep the same shape indicating that the reaction intermediates are not electroactive in the available potential range. Only a decrease in the peak current is observed. This can be attributed to the adsorption of molecules on a portion of the electrode surface which becomes inactive. This phenomenon is often present on voltammograms of redox active organic compounds.

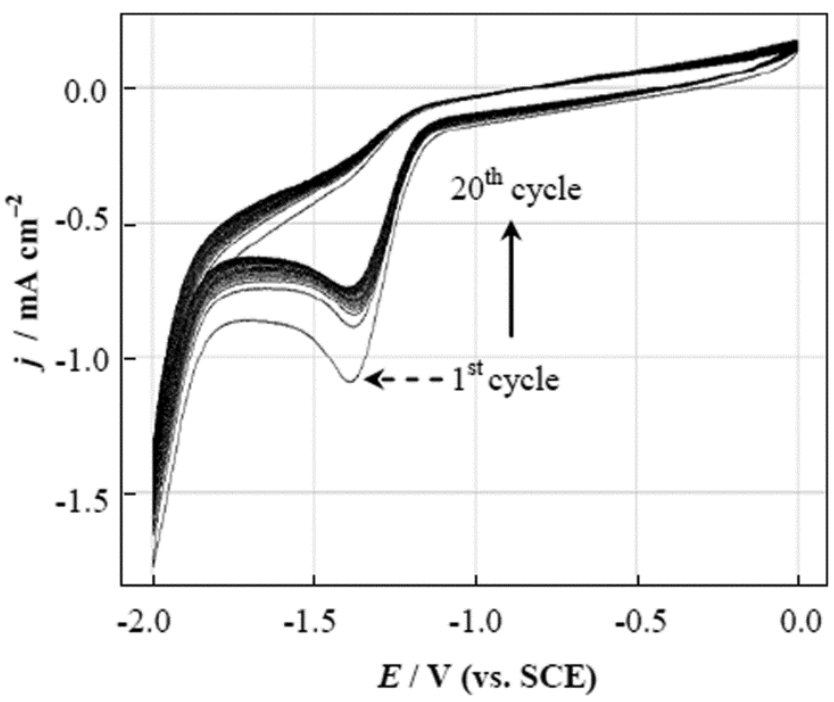

Figure 2. Repetitive cyclic voltammograms of the PGC electrode immersed in a solution containing $2.0 \mathrm{~g} \mathrm{~L}^{-1} \mathrm{Na}_{2} \mathrm{SO}_{4}+0.5 \mathrm{~g} \mathrm{~L}^{-1}$ IMD. $\mathrm{pH}=7, v=100 \mathrm{mV} \mathrm{s}^{-1}$ and $T=25^{\circ} \mathrm{C}$

\subsubsection{Effect of potential scan rate}

The cyclic voltammogram of IMD solution was recorded at different scan rates Figure 3. As the scan rate increased from 10 to $500 \mathrm{mV} \mathrm{s}^{-1}$, the peak current increased. A linear relationship was obtained between the logarithm of the peak current and the logarithm of the scan rate (eq. (1)) with a slope of 0.48 (inset of Figure 3 ). This value indicates that the IMD reaction is purely diffusion-controlled (Ronald et al., 2006).

$$
\log \left|j_{p}\right|\left(\mathrm{mAcm}^{-2}\right)=0.48 \log v\left(\mathrm{Vs}^{-1}\right)+0.46 \quad(r=0.998)
$$

For an irreversible reduction process, the theoretical relationship between the peak current $\left(j_{p}\right)$ and the voltage scan rate $(v)$ is given by the following equation (Bard and Faulkner, 1980):

$\mathrm{j}_{\mathrm{p}}=-2.9910^{5} \mathrm{n}\left(\alpha \mathrm{n}_{\mathrm{a}}\right)^{1 / 2} \mathrm{c}(\mathrm{D})^{1 / 2}(\mathrm{v})^{1 / 2}$

where, $\mathrm{j}_{\mathrm{p}}$ is the cathodic peak current $\left(A \mathrm{~cm}^{-2}\right), n$ is the number of electron equivalents exchanged during the reduction reaction, $\alpha$ is the charge-transfer coefficient, $n_{a}$ the number of electrons involved in the rate-determining step of the electrode process, $D$ the diffusion coefficient $\left(\mathrm{cm}^{2} \mathrm{~s}^{-1}\right), c$ is the bulk concentration of the diffusing species $\left(\mathrm{mol} \mathrm{cm}^{-3}\right)$ and $v$ is the potential scan rate $\left(\mathrm{V} \mathrm{s}^{-1}\right)$.
In addition, the peak potential $E_{\mathrm{p}}$ is shifted to more negative values with increasing the scan rates, confirming the irreversible nature of the reduction process (Figure 3 ).

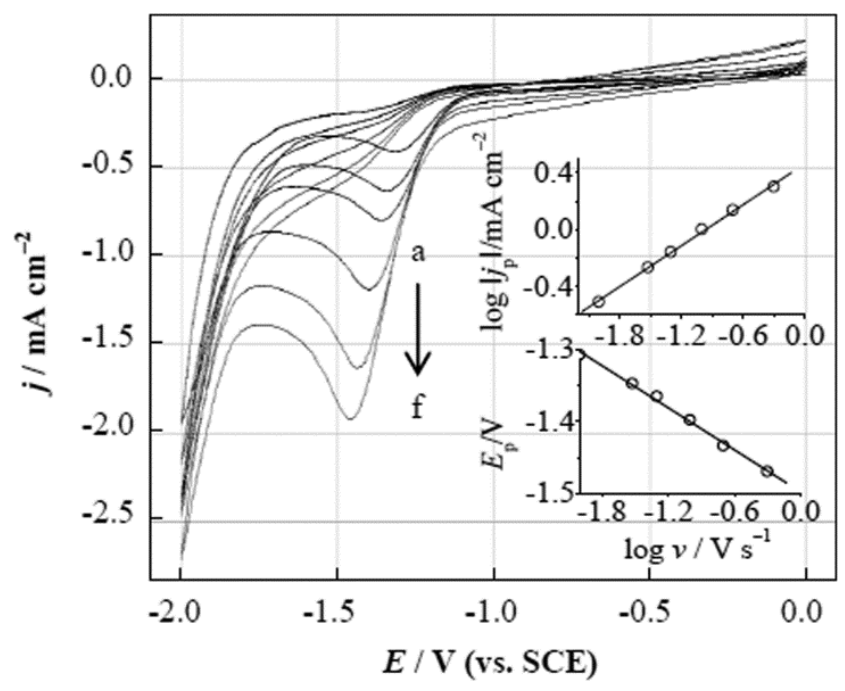

Figure 3. Voltammograms of the first redox cycle of the PGC electrode immersed in a solution containing $2.0 \mathrm{~g} \mathrm{~L}^{-1} \mathrm{Na}_{2} \mathrm{SO}_{4}+$ $0.5 \mathrm{~g} \mathrm{~L}^{-1} \mathrm{IMD}$ recorded at different scan rates. (a) 10; (b); 30 (c) 50; (d) 100; (e) 200 and (f) $500 \mathrm{mV} \mathrm{s}^{-1}$. The inset panels show the plot of $\log \mid j p l$ and $E p$ as a function of $\log v . \mathrm{pH}=7$ and $T=25^{\circ} \mathrm{C}$

For an irreversible electrode process, $E_{\mathrm{p}}$ can be defined by the following equation at $25^{\circ} \mathrm{C}$ (Ender and Cabir, 2009).

$E_{p}=E^{\circ}-2.3 \frac{R T}{\alpha n_{a} F}\left[\log \left(\frac{D^{1 / 2}}{k^{\circ}}\right)+\log \left(\frac{\alpha n_{a} F v}{R T}\right)^{1 / 2}+0.34\right]$

where, $E_{\mathrm{p}}$ is the peak potential $(\mathrm{V}), E^{0}$ is the standard potential $(\mathrm{V}), \mathrm{R}$ is the gas constant $\left(8.314 \mathrm{~J} \mathrm{~K}^{-1} \mathrm{~mol}^{-1}\right), T$ is the temperature $(K), F$ is the Faraday constant $(96,485 \mathrm{C}$ $\mathrm{mol}^{-1}$ ) and $k^{\circ}$ is the standard rate constant of the electrochemical reaction.

The inset of Figure 3 displays a linear relationship between $E_{p}$ and logarithm of scan rate (eq. (4)).

$$
E_{p}(V)=-0.08 \log v\left(V^{-1}\right)-1.49 \quad(r=0.997)
$$

Moreover, it is known that a rate-determining electron transfer is always a one-electron process $\left(n_{\mathrm{a}}=1\right)$ and $\alpha$ generally varies between 0.3 and 0.7 (Kumari and Sharma, 2011a; Kumari and Sharma, 2011b). From the slope of eq. (4), the charge transfer coefficient $\alpha=0.37$ suggests that the reduction process is irreversible.

\subsubsection{Effect of $p H$}

The effect of the solution $\mathrm{pH}$ on the electrochemical reduction of $0.5 \mathrm{~g} \mathrm{~L}^{-1} \mathrm{IMD}$ was studied in the $\mathrm{pH}$ range of 3-11 at the PGC electrode. The results reveal that all voltammograms demonstrate a single cathodic peak regardless of $\mathrm{pH}$ (Figure 4).

However, the absolute value of the current of this peak increased significantly with increasing the $\mathrm{pH}$ value from 3 to 7 . It reached a maximum level at $\mathrm{pH} 7$ and then decreased gradually above $\mathrm{pH}$ 7. This result is in good 
agreement with other studies on the determination of the nitro group containing neonicotinoid insecticides (Valeria et al., 2005; Zsigmond et al., 2009; Alberto et al., 1999). Thus, considering the sensitivity of the determination of IMD, pH 7 was selected for the succeeding analytical experiments. In accordance with the literature (Barek et al., 1994; de Cassia Silva et al., 2004; Yongnian et al., 2001), the electrochemical reduction of nitro-substituted compounds, in acid, neutral or basic medium, involves four electrons to give the corresponding hydroxylamine on two steps. The first reaction is slow (rate-determining step) and undergoes one-electron transfer $\left(n_{a}=1\right)$.

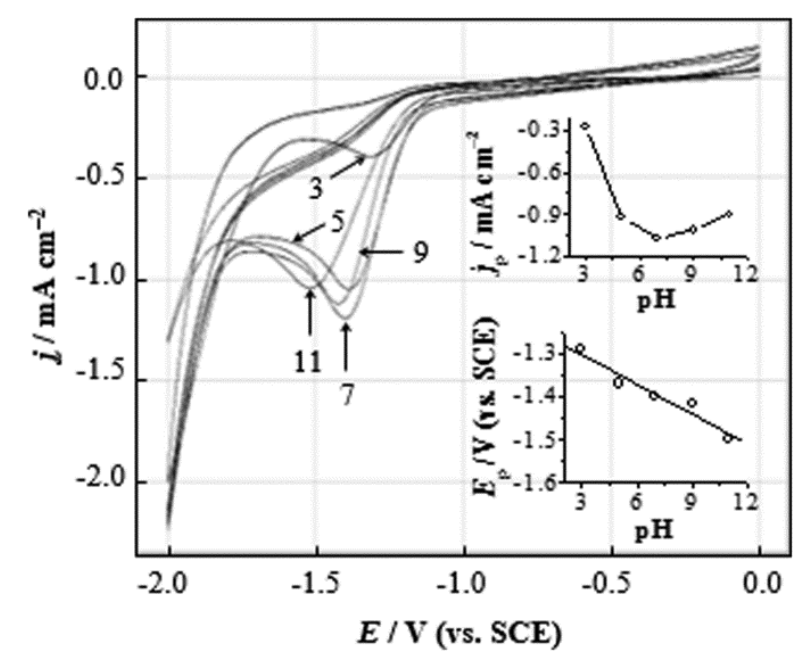

Figure 4. Voltammograms of the first redox cycle of the PGC electrode immersed in a solution containing $2.0 \mathrm{~g} \mathrm{~L}^{-1} \mathrm{Na}_{2} \mathrm{SO}_{4}+$ $0.5 \mathrm{~g} \mathrm{~L}^{-1} \mathrm{IMD}$ recorded at different $\mathrm{pH}$ (indicated). $v=100 \mathrm{mV} \mathrm{s}^{-1}$ and $T=25^{\circ} \mathrm{C}$<smiles>O=[N+]([O-])/N=C1/CCCN1Cc1ccc(Cl)nc1</smiles>
(Slow)

The second step is fast and involves three electrons and $\mathrm{pH}$-depending.

In acidic medium:

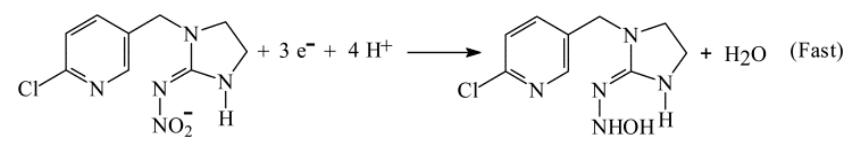

In neutral or basic medium:

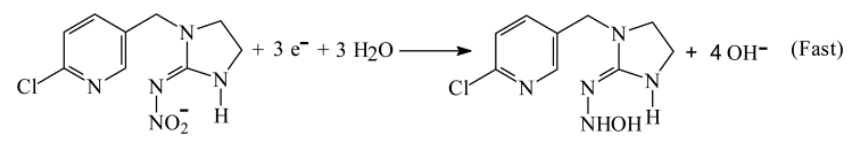

Moreover, increasing $\mathrm{pH}$ results in a negative shift of the peak potential $\left(E_{\mathrm{p}}\right)$ (inset of Figure 4). A linear relationship between $E_{\mathrm{p}}$ and $\mathrm{pH}$ was obtained. This linear relation can be expressed by (Eq. (5)).

$E_{p}(V)=-0.057 \mathrm{pH}-1.241 \quad(r=0.968)$

The $E_{p}$ values are shifted by increasing the $\mathrm{pH}$ by about 57 $\mathrm{mV}$ per $\mathrm{pH}$ unit in the $\mathrm{pH}$ range $3-11$, indicate that the ratio of the exchanged electrons and protons is most probably one.

\subsubsection{Effect of temperature}

The effect of temperature on the electrochemical behavior of IMD was studied in $2.0 \mathrm{~g} \mathrm{~L}^{-1} \mathrm{Na}_{2} \mathrm{SO}_{4}$ containing $0.5 \mathrm{~g} \mathrm{~L}^{-1} \mathrm{IMD}$ between -2.0 and $0.0 \mathrm{~V}$ at a scan rate of 100 $\mathrm{mV} \mathrm{s^{-1 }}$ and at temperatures between 25 and $60^{\circ} \mathrm{C}$. Cyclic voltammograms (Figure 5) show that the cathodic peak current increased with the increase of temperature.

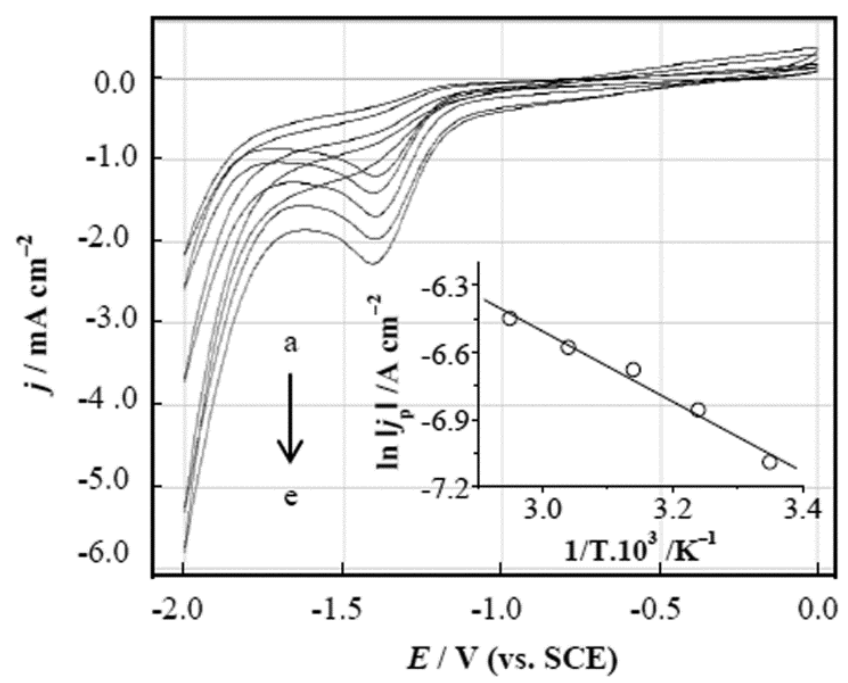

Figure 5. Voltammograms of the first redox cycle of the PGC electrode immersed in a solution containing $2.0 \mathrm{~g} \mathrm{~L}^{-1} \mathrm{Na}_{2} \mathrm{SO}_{4}+$ $0.5 \mathrm{~g} \mathrm{~L}^{-1} \mathrm{IMD}$ at different temperatures. The inset panel shows the Arrhenius-type plot of the peak current density. (a) 25, (b),

35 (c) 45 , (d) 55 and (e) $65^{\circ} \mathrm{C}$. $\mathrm{pH}=7$ and $v=100 \mathrm{mV} \mathrm{s}^{-1}$

The natural logarithm of the peak current increased linearly with the inverse of the temperature (Eq. (6)) as shown in the inset of Figure 5.

$\ln \left|\mathrm{j}_{\mathrm{P}}\right|=-1.57 \frac{1}{\mathrm{~T}}-1.78 \quad(\mathrm{r}=0.994)$

According to the Arrhenius equation, the activation energy $E_{a}$ was found to be $13 \mathrm{~kJ} \mathrm{~mol}^{-1}$. This value is less than $40 \mathrm{~kJ} \mathrm{~mol}^{-1}$, and thus confirms the fact that the electro-reduction of IMD on the electrode is diffusion-controlled (Belhadj-Tahar and Savall, 1998).

\subsection{Square wave voltammetric investigation}

SWV technique was employed to understand the electrochemical process of IMD occurring at PGC electrode. Figure 6 exhibits the square wave voltammograms recorded in the absence and presence of 
$0.5 \mathrm{~g} \mathrm{~L}^{-1}$ IMD in a solution of $2.0 \mathrm{~g} \mathrm{~L}^{-1} \mathrm{Na}_{2} \mathrm{SO}_{4}$. It is clear that, during the cathodic scan, a single reduction peak was observed at a potential of $-1.35 \mathrm{~V}$ (vs. SCE).

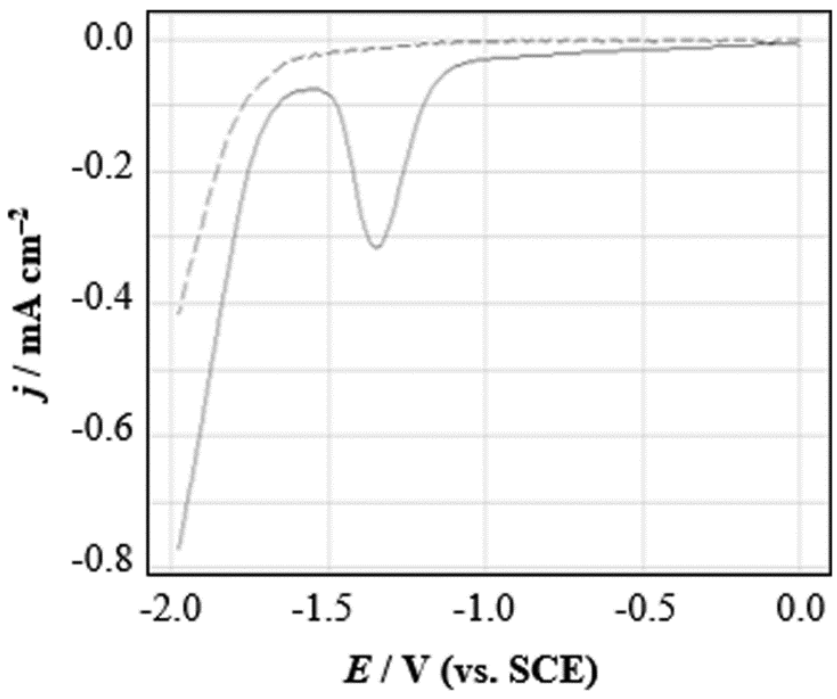

Figure 6. Square wave voltammograms of the IMD electrode immersed in a $2 \mathrm{~g} \mathrm{~L}^{-1} \mathrm{Na}_{2} \mathrm{SO}_{4}$ solution without (dotted curve) and with $0.5 \mathrm{~g} \mathrm{~L}^{-1} \mathrm{IMD}$ (solid curve). $f=100 \mathrm{~s}^{-1}, \Delta E_{a}=50 \mathrm{mV}, \Delta E_{i}=10$ $\mathrm{mV}, \mathrm{pH}=7$ and $T=25^{\circ} \mathrm{C}$

The optimization of the analytical method involved a systematic study of the experimental parameters that affect the SWV response, namely frequency $(f)$, pulse amplitude $\left(\Delta E_{a}\right)$ and scan increment $\left(\Delta E_{i}\right)$

\subsubsection{Effect of square wave frequency}

This parameter is important in SWV because it determines the intensity of the signal and, in turn, the sensitivity of the analytical methodology. Figure 7 illustrates the SW voltammograms obtained for different frequency values in the range of 20 to $100 \mathrm{~s}^{-1}$. The cathodic peak current increases by increasing the frequency value. The inset of Figure 7 shows a linear relationship between the logarithm of the peak current and the logarithm of the frequency with a slope of 0.51 (Eq. (7)). This value indicates that the IMD reaction is purely diffusion-controlled.

$\log \left|j_{P}\right|=0.51 \log f-1.56 \quad(r=0.998)$

Moreover, a linear relationship was obtained between the peak potential and the logarithm of the frequency (Eq. 8).

$E_{p}=-0.05 \log f-1.25 \quad(r=0.991)$

The slope of this straight line has been used to calculate $\alpha n$ value for the electrochemical reaction by means of Eq. (9) which is equal to 0.05 . It is clear from the literature that the number of electrons exchanged by the molecule of IMD has been assumed to be $n=4$ to give hydroxylamine. Therefore, the charge transfer coefficient $\alpha=0.3$ suggests that the reduction process is irreversible.
$\frac{\Delta E_{p}}{\Delta \log f}=-\frac{2.3 R T}{\alpha n F}$

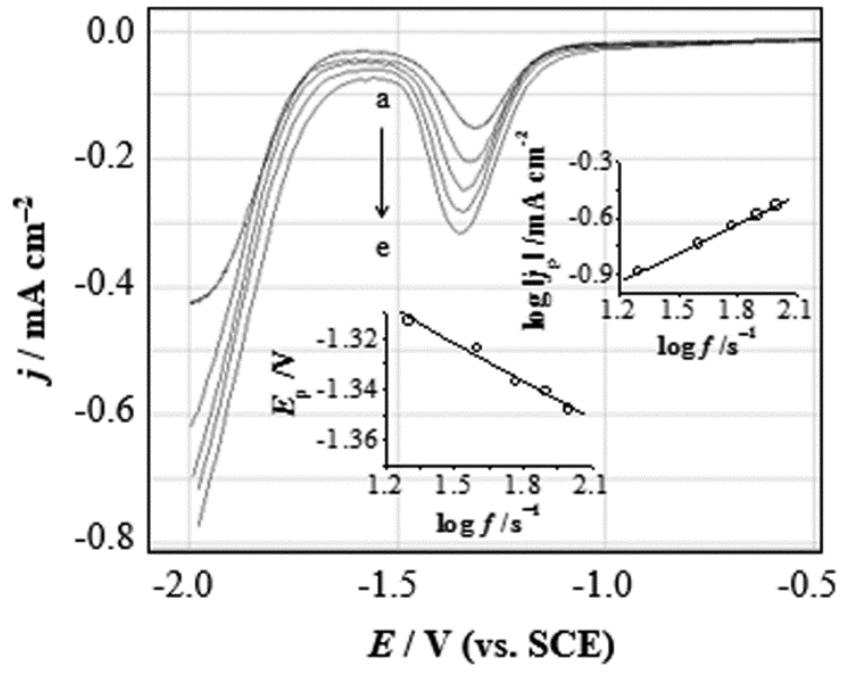

Figure 7. Square wave voltammograms of the PGC electrode immersed in a solution containing $2 \mathrm{~g} \mathrm{~L}^{-1} \mathrm{Na}_{2} \mathrm{SO}_{4}+0.5 \mathrm{~g} \mathrm{~L}^{-1} \mathrm{IMD}$ recorded at different frequency. $f:$ (a) 20, (b) 40, (c) 60, (d) 80 and (e) $100 \mathrm{~s}^{-1} . \Delta E_{a}=50 \mathrm{mV} ; \Delta E_{i}=10 \mathrm{mV} ; \mathrm{pH}=7$ and $T=25^{\circ} \mathrm{C}$

\subsubsection{Effect of pulse amplitude}

Another important parameter involved in SWV is the pulse amplitude $\left(\Delta E_{a}\right)$. The effect of pulse amplitude on the reduction peak current of $0.5 \mathrm{~g} \mathrm{~L}^{-1} \mathrm{IMD}$ in $2.0 \mathrm{~g} \mathrm{~L}^{-1}$ $\mathrm{Na}_{2} \mathrm{SO}_{4}$ of $\mathrm{pH}=7$ was studied by different values of pulse amplitudes from $10 \mathrm{mV}$ to $50 \mathrm{mV}$ at a frequency of $100 \mathrm{~s}^{-1}$ (Figure 8).

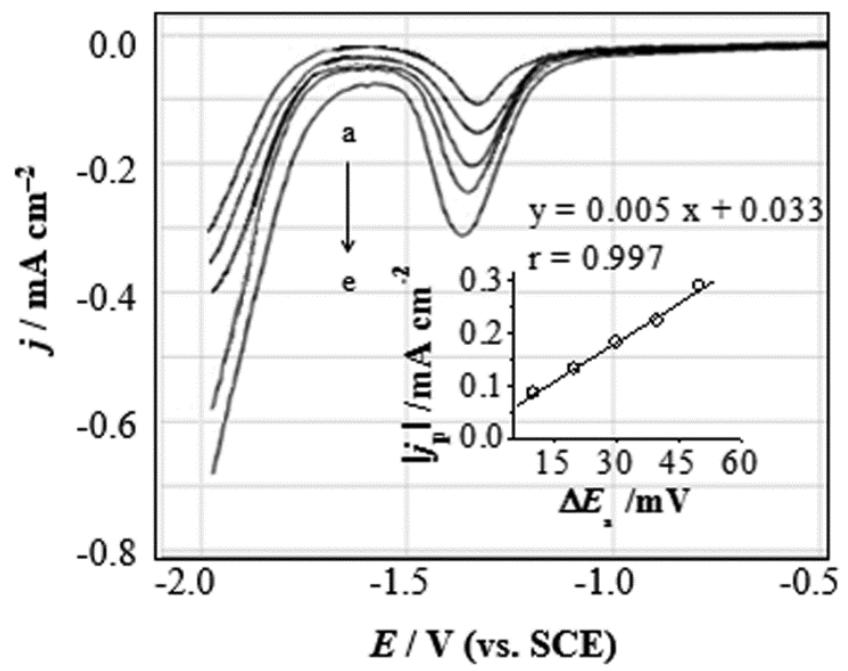

Figure 8. Square wave voltammograms of the PGC electrode immersed in a solution containing $2 \mathrm{~g} \mathrm{~L}^{-1} \mathrm{Na}_{2} \mathrm{SO}_{4}+0.5 \mathrm{~g} \mathrm{~L}^{-1} \mathrm{IMD}$ recorded at different pulse amplitude. $\Delta E_{\mathrm{a}}$ : (a) 10 , (b) 20, (c) 30 , (d) 40 and (e) $50 \mathrm{mV} . f=100 \mathrm{~s}^{-1}, \Delta E_{i}=10 \mathrm{mV}, \mathrm{pH}=7$ and $T=25^{\circ} \mathrm{C}$

The results indicated that the peak current increased when the pulse amplitude increased from 10 to $50 \mathrm{mV}$. Therefore, at pulse amplitude of $50 \mathrm{mV}$, the peak current was found to be much sharper and defined. 


\subsubsection{Effect of scan increment}

This parameter, which allows determining the amount of potential changes between two data points in the experiment, was investigated. The effect of the scan increment $\left(\Delta E_{i}\right)$ on the electrochemical reduction of IMD by SWV was studied in the range of 2 to $10 \mathrm{mV}$ on the PGC electrode in the presence of $0.5 \mathrm{~g} \mathrm{~L}^{-1}$ IMD. Figure 9 reveals that the peak current enhanced upon the increase of scan increment $(2-10 \mathrm{mV})$. Therefore, a scan increment of $10 \mathrm{mV}$ was preferable in the present study.

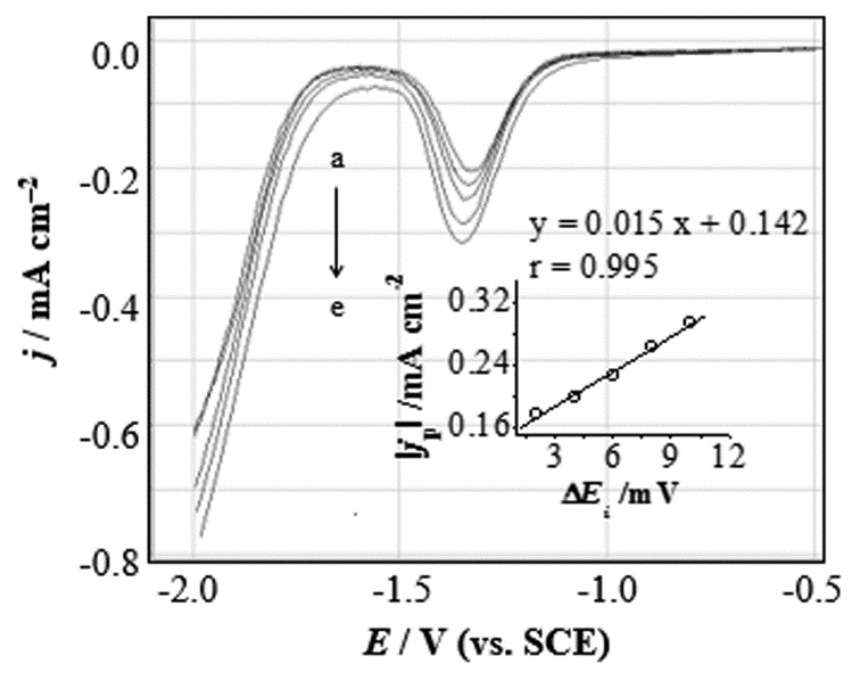

Figure 9. Square wave voltammograms of the $\mathrm{PGC}$ electrode immersed in a solution containing $2 \mathrm{~g} \mathrm{~L}^{-1} \mathrm{Na}_{2} \mathrm{SO}_{4}+0.5 \mathrm{~g} \mathrm{~L}^{-1} \mathrm{IMD}$ recorded at different scan increment. $\Delta \mathrm{E}_{\mathrm{i}}$ : (a) 2, (b) 4 , (c) 6 , (d) 8 and (e) $10 \mathrm{mV} . \mathrm{f}=100 \mathrm{~s}^{-1}, \Delta \mathrm{E}_{\mathrm{a}}=50 \mathrm{mV}, \mathrm{pH}=7$ and $\mathrm{T}=25^{\circ} \mathrm{C}$

\subsection{Calibration curve}

After selecting the most suitable conditions, the determination of IMD concentration using PGC and BDD electrodes was performed with $\mathrm{CV}$ and SWV techniques. Figures 10 and 11 display the cyclic and the square wave voltammograms obtained for different concentrations of IMD in $2.0 \mathrm{~g} \mathrm{~L}^{-1} \mathrm{Na}_{2} \mathrm{SO}_{4}$ at $\mathrm{pH} 7$. A well-defined single irreversible cathodic peak, proportional to the concentration of the IMD, was observed. A linear relationship between the reduction current and the IMD concentration was obtained for both methods. LOD and LOQ of IMD were calculated from the calibration curve using the following equations:

The LOD and LOQ were calculated using the following equations (Skoog et al., 1998).

$\operatorname{LOD}=\frac{3 \mathrm{~s}}{\mathrm{~m}}$

$\mathrm{LOQ}=\frac{10 \mathrm{~s}}{\mathrm{~m}}$

where $\mathrm{s}$ is the standard deviation of the intercept and $m$ is the slope of the calibration curve. In this way, the LOD and the LOQ were, respectively, 8.7 and $29.1 \mathrm{mg} \mathrm{L}^{-1}$ for CV.
By SWV, a linear relationship between the SWV current and IMD concentration was obtained covering two linear ranges from $1.25-100 \mathrm{mg} \mathrm{L}^{-1}$ and $100-500 \mathrm{mg} \mathrm{L}^{-1}$. The lower linear range was used for calculating the LOD and the LOQ, which were equal to 2.8 and $9.3 \mathrm{mg} \mathrm{L}^{-1}$, respectively. This result indicates that the SWV technique has relatively better sensitivity for detecting the IMD than the CV technique (Table 1).

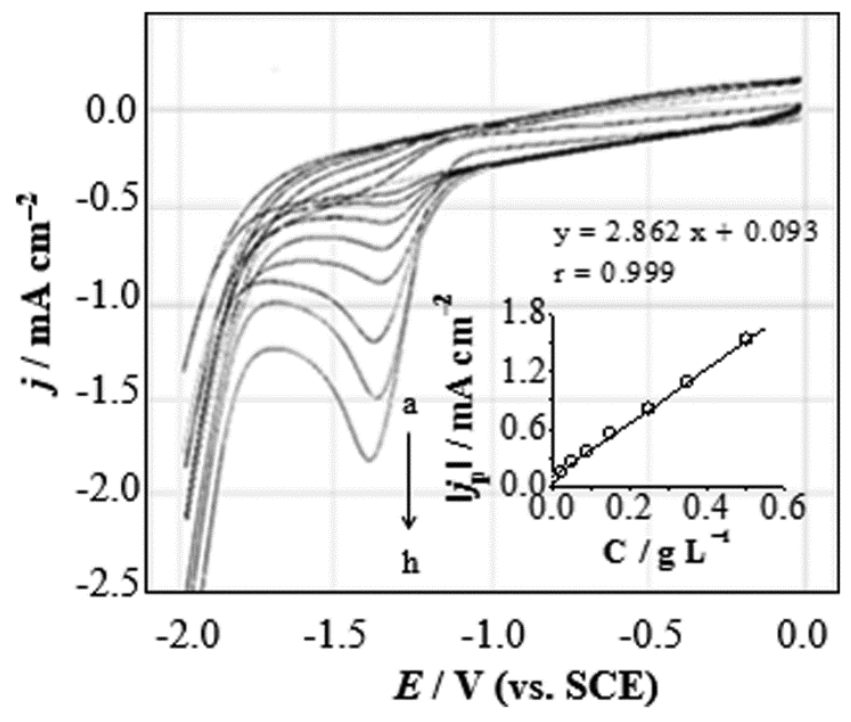

Figure 10. Voltammograms of the first redox cycle of the PGC electrode immersed in a solution containing $2 \mathrm{~g} \mathrm{~L}^{-1} \mathrm{Na}_{2} \mathrm{SO}_{4}+\mathrm{IMD}$ at different concentrations. IMD: (a) 5, (b) 20, (c) 50, (d) 90, (e) 150, (f) 250 , (g) 350 , (h) $500 \mathrm{mg} \mathrm{L}^{-1} \cdot v=500 \mathrm{mV} \mathrm{s}^{-1}, \mathrm{pH}=7$ and $T=$ $25^{\circ} \mathrm{C}$

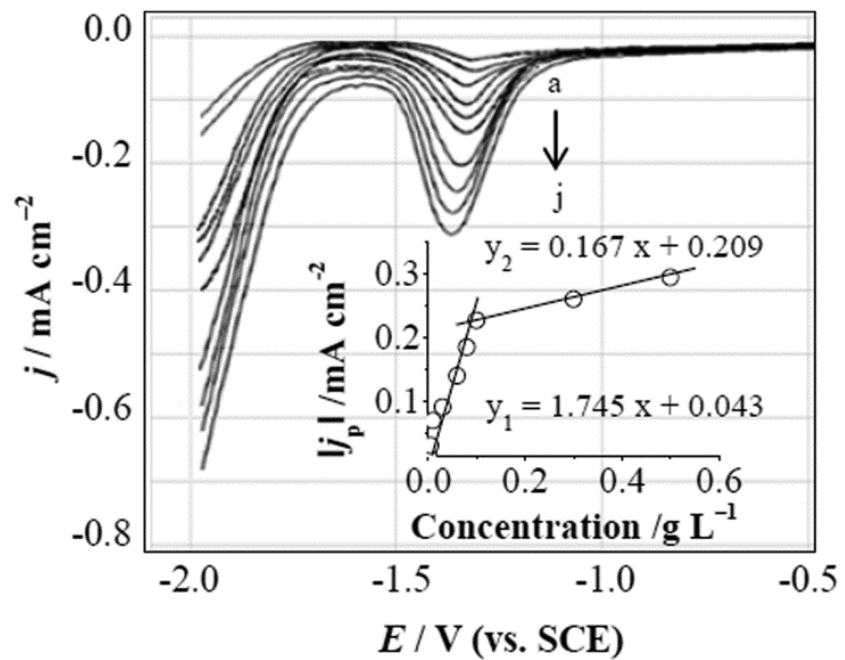

Figure 11. Square wave voltammograms of the PGC electrode immersed in a solution containing $2 \mathrm{~g} \mathrm{~L}^{-1} \mathrm{Na}_{2} \mathrm{SO}_{4}+\mathrm{NCD}$ at different concentrations. IMD: (a) $1.2510^{-3}$, (b) $2.510^{-3}$,

(c) $510^{-3}$, (d) $10^{-2}$, (e) $310^{-2}$, (f) $610^{-2}$, (g) $810^{-2}$, (h) 0.1 , (i) 0.3 , (j) $0.5 \mathrm{~g} \mathrm{~L}^{-1} . f=100 \mathrm{~s}^{-1}, \Delta E_{\mathrm{a}}=50 \mathrm{mV}, \Delta E_{i}=10 \mathrm{mV}, \mathrm{pH}=7$ and $T=$ $25^{\circ} \mathrm{C}$

On the other hand, Table 2 compares the performance of the proposed approaches with several voltammetric electrochemical methods reported in the literature for IMD determination. 
As can be seen from this table, the proposed approaches are the most sensitive method that used a bare electrode; however, it is less sensitive only than the methodologies that used complex and modified electrodes.

Table 1. Determination of IMD by CV and SWV techniques

\begin{tabular}{ccc}
\hline Parameter & \multicolumn{2}{c}{ Techniques } \\
\hline & CV (PGC) & SWV (PGC) \\
\hline Linearity range $\left(\mathrm{mg} \mathrm{L}^{-1}\right)$ & $5-500$ & $1.25-100$ \\
\hline Intercept $\left(\mathrm{mA} \mathrm{cm}^{-2}\right)$ & 0.093 & 0.043 \\
\hline SD of intercept $\left(\mathrm{mA} \mathrm{cm}^{-2}\right)$ & 0.00832 & 0.00162 \\
\hline Slope $\left(\mathrm{mA} \mathrm{cm}^{-2} \mathrm{~L} \mathrm{mg}^{-1}\right) \times 103$ & 2.868 & 1.745 \\
\hline Regression coefficient & 0.999 & 0.998 \\
\hline Number of data points & 8 & 10 \\
\hline LOD $\left(\mathrm{mg} \mathrm{L}^{-1}\right)$ & 8.7 & 2.8 \\
\hline LOQ $\left(\mathrm{mg} \mathrm{L}^{-1}\right)$ & 29.1 & 9.3
\end{tabular}

As can be seen from this table, the proposed approaches are the most sensitive method that used a bare electrode; however, it is less sensitive only than the methodologies that used complex and modified electrodes.

The repeatability and reproducibility of results are excellent. In fact, to evaluate these properties, two IMD solutions ( 5 and $20 \mathrm{mg} \mathrm{L}^{-1}$ ) were tested four times by CV and SWV techniques. With respect to the CV technique, the repeatability of the current measurement was $1.12 \%$ RSD for $5 \mathrm{mg} \mathrm{L}^{-1}$ and $1.21 \%$ RSD for $20 \mathrm{mg} \mathrm{L}^{-1}$. However, by using the SWV technique the repeatability was $1.3 \%$ RSD for $5 \mathrm{mg} \mathrm{L}^{-1}$ and $1.5 \%$ RSD for $20 \mathrm{mg} \mathrm{L}^{-1}$.

The reproducibility of the current measurement was also calculated $0.97 \%$ RSD for $5 \mathrm{mg} \mathrm{L}^{-1}$ and $0.88 \%$ RSD for 20 $\mathrm{mg} \mathrm{L}^{-1}$ by CV technique. When using the SWV, the RSD were $0.93 \%$ for $5 \mathrm{mg} \mathrm{L}^{-1}$ and $1.1 \%$ for $20 \mathrm{mg} \mathrm{L}^{-1}$. The low values of relative standard deviation (RSD) indicate good precision and reproducibility of the proposed CV and SWV methods for the assay of IMD.

Table 2. Comparison of the efficiency of some voltammetric methods in the determination of IMD

\begin{tabular}{cccccc}
\hline Electrode & Methods & Range $\left(\mathbf{m g ~ L}^{-1}\right)$ & LOD $\left(\mathbf{m g ~ L}^{-1}\right)$ & LOQ $\left(\mathbf{m g ~ L}^{-1}\right)$ & References \\
\hline BDD & SWV & $7.5-51$ & 2.2 & 7.3 & Ben Brahim et al. (2016) \\
\hline CPE & DPV & $1.7-30$ & 0.52 & 1.73 & Papp et al. (2009) \\
\hline PGC & SWV & $1.25-100$ & 2.8 & 9.3 & Present Work \\
\hline PGC & CV & $5-500$ & 8.7 & 29.1 & Present Work \\
\hline GCE & CV & $2.7-500$ & 7.6 & 25.9 & Guzsvany et al. (2005) \\
\hline BiFE & DPV & $2.5-51$ & 2.9 & - & Guzsvany et al. (2008) \\
\hline \multirow{2}{*}{$\mathrm{nAgn}_{\mathrm{f}} / \mathrm{nTiO}_{2} \mathrm{n}_{\mathrm{f}} / \mathrm{GCE}$} & $\mathrm{CV}$ & $0.25-1.7$ & 0.63 & 2.1 & \multirow{2}{*}{ Kumaravel et al. (2011) } \\
\cline { 2 - 5 } & $\mathrm{DPV}$ & $0.12-0.85$ & 0.006 & 0.021 & \\
\hline
\end{tabular}

Abbreviations: GCE, Glassy carbon electrode; CPE, Carbon-paste electrode; nAgnf/nTiO2nf/GCE, nanosilver Nafion ${ }^{\circledR} /$ nanoTiO $_{2} \mathrm{Nafion}^{\circledR}$ modified glassy carbon electrode; BiFE, Bismuth-film electrode; BDD, Boron-Doped Diamond.

Table 3. Analytical parameters obtained at a PGC for the determination of IMD in plum and peaches juices using CV and SWV techniques

\begin{tabular}{|c|c|c|c|c|c|}
\hline Methods & Juice & $\begin{array}{l}\text { Added amount } \\
\qquad\left(\mathrm{mg} \mathrm{L}^{-1}\right)\end{array}$ & $\begin{array}{l}\text { Found amount } \\
\qquad\left(\mathrm{mg} \mathrm{L}^{-1}\right)\end{array}$ & Recovery (\%) & RSD (\%) \\
\hline \multirow{6}{*}{$\mathrm{CV}$} & \multirow{3}{*}{ Plum } & 20 & 20.48 & 102.4 & 0.98 \\
\hline & & 10 & 9.86 & 98.6 & 0.87 \\
\hline & & 5 & 4.97 & 99.5 & 1.03 \\
\hline & \multirow{3}{*}{ Peaches } & 20 & 19.72 & 98.6 & 1.05 \\
\hline & & 10 & 9.79 & 97.9 & 0.99 \\
\hline & & 5 & 5.05 & 101 & 1.10 \\
\hline \multirow{6}{*}{ SWV } & \multirow{3}{*}{ Plum } & 20 & 21.28 & 106.4 & 1.04 \\
\hline & & 10 & 11.3 & 113 & 0.96 \\
\hline & & 5 & 5.35 & 107 & 1.21 \\
\hline & \multirow{3}{*}{ Peaches } & 20 & 20.36 & 101.8 & 0.96 \\
\hline & & 10 & 10.3 & 103 & 1.24 \\
\hline & & 5 & 5.90 & 118 & 1.33 \\
\hline
\end{tabular}

The recovery efficiencies ( $\mathrm{R} \%$ ) for the different systems under investigation were calculated using equation (12):

$$
\mathrm{R}(\%)=\frac{[\mathrm{IMD}]_{\text {found }}}{[\mathrm{IMD}]_{\text {added }}} \times 100
$$

The analysis of the peak current showed that the obtained values of recovery ranged from $95.4 \%$ to $100.1 \%$ by CV technique and $100.22 \%$ to $100.4 \%$ by SWV. These average percent recoveries obtained indicate the good accuracy of these methods. 


\subsection{Determination of $I M D$ in plum and peach fruits}

The applicability of the CV and SWV methods was tested by determining the IMD in real samples namely plum and peach juices. The IMD content in the fruit juice samples were determined by measuring the peak current from the calibration curves in Figures 10 and 11. The amounts of this pesticide were added to yield concentrations in the range between $5 \mathrm{mg} \mathrm{L}^{-1}$ and $20 \mathrm{mg} \mathrm{L}^{-1}$.

As can be seen from Table 3, the obtained recovery was in the range $97.9-102.4 \%$ by CV and $101.8 \%-118 \%$ by SWV which indicates that the developed methods can be applied for quantitative determination of IMD in fruit juices. The RSD ranged from $0.87 \%-1.1 \%$ and $0.96 \%-1.33 \%$, respectively, by CV and SWV. The low values of RSD indicate good precision and reproducibility of the CV and SWV methods and the average percent recoveries obtained were quantitative, indicating good accuracy of the methods.

\section{Conclusion}

CV and SWV methods have been proved to be very sensitive for the determination of organic molecules including IMD. This work is the basis for the development of voltammetric methods for the determination of IMD in commercial formulations. All experimental and instrumental parameters were optimized as their values strongly affect the sensitivity of the voltammetric methods. The LOD and LOQ values obtained by these methods were determined and the result has found that the SWV is more sensitive than the CV. It was also demonstrated that these methods were satisfactorily applied to the determination of IMD in real samples such as plum and peach juice.

\section{Acknowledgment}

This work was financially supported by the Tunisian Higher Education and Scientific Research Ministry.

\section{References}

Alberto N., Antonio G., Rachid E., Jose L.V. and Amadeo R.F. (1997), Determination of imidacloprid in vegetable samples by gas chromatography-mass spectrometry, Analyst, 122, 579-581.

Alberto N., Rachid E., Antonio G. and José L.V. (1999), Differential-pulse polarographic determination of the insecticide imidacloprid in commercial formulations, Microchimica Acta, 130, 261-265.

Bard A.J. and Faulkner L.R. (1980), In Electrochemistry: Principles, Methods and Applications, Ed., John Wiley \& Sons, Inc., New York.

Barek J., Ebertova H., Mejstrik V. and Zima J. (1994), Determination of 2-nitrophenol, 4-nitrophenol, 2-methoxy5-nitrophenol, and 2,4-dinitrophenol by differential pulse voltammetry and adsorptive stripping voltammetry, Collection of Czechoslovak Chemical Communications, 59, 1761-1771.

Baskaran S., Kookana R.S. and Naidu R. (1997), Determination of the insecticide imidacloprid in water and soil using highperformance liquid chromatography, Journal of Chromatography A, 787, 271-275.
Belhadj-Tahar N. and Savall A. (1998), Mechanistic aspects of phenol electrochemical degradation by oxidation on a $\mathrm{Ta} / \mathrm{PbO}_{2}$ anode, Journal of the Electrochemical Society, 145, 3427-3434.

Ben Brahim M., Belhadj Ammar H., Abdelhedi R. and Samet Y. (2016), Electrochemical behavior and analytical detection of Imidacloprid insecticide on BDD electrode using square-wave voltammetric method, Chinese Chemical Letters, 27, 666672.

Blasco C., Font G. and Pico Y. (2002), Comparison of microextraction procedures to determine pesticides in oranges by liquid chromatography-mass spectrometry, Journal of Chromatography A, 970, 201-212.

Chao S.L. and Casida J.E. (1997), Interaction of imidacloprid metabolites and analogs with the nicotinic acetylcholine receptor of mouse brain in relation to toxicity, Pesticide Biochemistry and Physiology, 58, 77-88.

Chin-Chen M.L., Esteve-Romero J. and Carda-Broch S. (2009), Determination of the insecticide imidacloprid in fruit juices using micellar high-performance liquid chromatography, Journal of AOAC International, 92, 1551-1556.

de Cassia Silva L.R., Damos F.S., de Oliveira A.B., Beck J. and Kubota L.T. (2004), Voltammetric determination of 4-nitrophenol at a lithium tetracyanoethylenide (LiTCNE) modified glassy carbon electrode, Talanta, 64, 935-942.

Di Muccio A., Fidente P., Barbini D.A., Dommarco R., Seccia S. and Morrica P. (2006), Application of solid-phase extraction and liquid chromatography-mass spectrometry to the determination of neonicotinoid pesticide residues in fruit and vegetables. Journal of Chromatography A, 1108, 1-6.

Ender B. and Cabir A. (2009), A voltammetric study on the aqueous electrochemistry of acid red 1 (Azophloxine), Croatica Chemica Acta, 82, 583-593.

Fernández-Alba A.R., Tejedor A., Aguera A., Contreras M. and Garrido J. (2000), Determination of imidacloprid and benzimidazole residues in fruits and vegetables by liquid chromatography-mass spectrometry after ethyl acetate multiresidue extraction, Journal of AOAC Internationa, 83, 748-755.

Fidente P., Seccia S., Vanni F. and Morrica P. (2005), Analysis of nicotinoid insecticide residues in honey by solid matrix partition cleanup and liquid chromatography-electrospray mass spectrometry, Journal of Chromatography A, 1094, 175-178.

Guiberteau A., Galeano T., Mora N., Parrilla P. and Salinas F. (2001), Study and determination of the pesticide imidacloprid by square wave adsorptive stripping voltammetry, Talanta, 53, 943-949.

Jin G. and Hu X. (2008), Study and determination of pesticide imidacloprid by linear sweep voltammetry at a prussian blue and multi-walled carbon nanotubes (MWNT) modified glassy carbon electrode, Chinese Journal of Analysis Laboratory, 27, 4-7.

Kumaravel A. and Chandrasekaran M (2011), Electrochemical determination of imidacloprid using nanosilver Nafion ${ }^{\circledR} /$ nanoTiO 2 Nafion ${ }^{\circledR}$ composite modified glassy carbon electrode, Sensors and Actuators B: Chemical, 158, 319-326.

Kumari M. and Sharma D.K. (2011a), Synthesis of (1-ethyl-2phenyl-1, 4-dihydroquinolin-4-yl)-(2, 4, 6-trimethylphenyl) amine by electrochemical methods in aprotic media, Croatica Chemica Acta, 84, 455-460. 
Kumari M. and Sharma D.K. (2011b), Electrochemical behaviour of (2,4-difluoro-phenyl)-(2-phenyl-1H-quinolin-4-ylidene)amine in aprotic media, Journal of the Korean Chemical Society, 55, 50-56.

Lee J.K., Ahn K.C., Park O.S., Kang S.Y. and Hammock B.D. (2001), Development of an ELISA for the Detection of the Residues of the Insecticide Imidacloprid in Agricultural and Environmental Samples, Journal of Agricultural and Food Chemistry, 49, 2159-2167.

Liu H., Song J., Zhang S., Qu L., Zhao Y., Wu Y. and Liu H. (2005), Analysis of residues of imidacloprid in tobacco by high-performance liquid chromatography with liquid-liquid partition cleanup, Pest Management Science, 61, 511-514.

Majidi M.R., Karim A., Mehdi B. and Mohmmad N. (2011), Determination of imidacloprid in tomato grown in Greenhouse based on copper(II) phthalocyanine modified carbon ceramic electrode by differential pulse voltammetry, Journal of the Chinese Chemical Society, 58, 207-214.

Mandic A., Lazic S., Okresz S.Z. and Gaal F. (2005), Determination of the Insecticide Imidacloprid in Potato (Solanum tuberosum L.) and Onion (Allium cepa) by High-Performance Liquid Chromatography with Diode-Array Detection, Journal of Analytical Chemistry, 60, 1134-1138.

Matsuda K., Shimomura M., Ihara M., Akamatsu M. and Sattelle D.B. (2005), Neonicotinoids show selective and diverse actions on their nicotinic receptor targets: electrophysiology, molecular biology, and receptor modeling studies, Bioscience, Biotechnology, and Biochemistry, 69, 1442-1452.

McCreery R.L. (1991), In Electroanalytical Chemistry, Bard A.J., Ed.; Marcel D., New York.

Obana H., Okihashi M., Akutsu K., Kitagawa Y. and Hori S. (2002), Determination of acetamiprid, imidacloprid, and nitenpyram residues in vegetables and fruits by high-performance liquid chromatography with diode array detection, Journal of Agricultural and Food Chemistry, 50, 4464-4467.

Ronald J.M., Irishi N.N., Sherigara B.S. and Vijayakumar K.R. (2006), A study of quasi reversible nitro radical anion from $\beta$ nitrostyrene at wax-impregnated carbon paste electrode, Journal of Chemical Sciences, 118, 275-279.

Skoog D.A., Holler F.J. and Nieman T.A. (1998), Eds. In Principles of Instrumental Analysis; 5th ed., Saunders College Publishing: Philadelphia.

Ting K.C., Zhou E.G. and Saini N. (2004), Determination of imidacloprid in fruits and vegetables by liquid chromatography with diode array and nitrogen-specific chemiluminescence detection, Journal of AOAC Internationa, 87, 997-1002.

Tomlin C. (2000), In: The Pesticide Manual: A World Compendium, 12th ed., British Crop Protection Council, Farnham, United Kingdom.

Valeria G., Ferenc G., Luka B. and Silvija O. (2005), Voltammetric determination of imidacloprid and thiamethoxam., Journal of the Serbian Chemical Society, 70, 735-743.

Vilchez J.L., El-Khattabi R., Blanc R. and Navalon A. (1998), Photochemical-fluorimetric method for the determination of the insecticide imidacloprid in water samples, Analytica Chimica Acta, 371, 247-253.

Vilchez J.L., Valencia M.C, Navalon A., Molinero-Morales B. and Capitan-Vallvey L.F. (2001), Flow injection analysis of the insecticide Imidacloprid in water samples with photochemically induced fluorescence detection, Analytica Chimica Acta, 439, 299-305.

Wang J. and Zhang W. (2012), Electrochemical behavior of imidacloprid, Journal of Electrochemistry, 18, 68-72.

Wu L., Qiuju W., Weimeng S., Zhenyan G., Yuehua Z., Jiping D. and Qingli H. (2013), Electrochemical determination of imidacloprid using poly(carbazole)/chemically reduced grapheme oxide modified glassy carbon electrode, Sensors and Actuators B: Chemical, 183, 102-109.

Yongnian N., Li W. and Serge K. (2001), Simultaneous determination of nitrobenzene and nitro-substituted phenols by differential pulse voltammetry and chemometrics, Analytica Chimica Acta, 431, 101-113.

Zsigmond P., Ivan S., Valéria G., Karel V. and Ferenc G. (2009), Voltammetric determination of imidacloprid insecticide in selected samples using a carbon paste electrode, Microchimica Acta, 166, 169-175. 